\title{
A NEW PARADIGM OF PUBLICNESS IN CONJUNCTION WITH PUBLIC SECTOR REFORM
}

\author{
Yuji Sato* \\ Graduate School of Policy Sc ience \\ Mie Chukyo University \\ Matsusaka, Mie, JAPAN \\ E-mail: ysatoh@mie-chukyo-u.sc.jp
}

\begin{abstract}
This paper shows a new paradigm of publicness in conjunction with public sector reform by applying the Analytic Hierarchy Process (AHP) and principal component analysis. Specifically, based on the rational matching process of projects of a local government with alternative sectors employing the AHP, this paper proposes a new paradigm of publicness by using principal component analys is concerning properties of projects of a local government. The process clarifies both the property of each project of a local government and the characteristic of alternative sectors including public sector, and the analysis extracts four new concepts representing the features of the projects. The scatter diagram of the projects plotted on the plane coordinated by the new concepts illustrates characteristic distribution of projects, which implies which project should be administrated by which sector. The result of this paper shows a new paradigm of publicness and implies how to promote public sector reform.
\end{abstract}

Keywords: publicness, administrative evaluation, public sector reform

\section{Introduction}

An evaluation of public activities consists of a series of processes evaluating the adequacy and achievement of the polic ies and measures of public administration against a specific benchmark. In Japan, a prefecture first introduced a rigorous administrative evaluation system in 1996. Since then, some local governments have begun to introduce a variety of such evaluation systems. As of the end of September $2009,98 \%$ of prefectural government, all 18 major cities, and more than $48 \%$ of the local authorities, have introduced their original evaluation systems (Ministry of Internal Affairs and Communications, 2011).

On the other hand, public sector reform encompasses a spectrum of issues including civil service reform, performance measurement, and governance regulations. The separation of implementation of administrative activities from decision-making has been diffused as "agencification" around the world. The central government of Japan has also adopted such reform where the agencies are called "independent administrative institutions" (Yamamoto 2008). A great many projects of the local government, however, have not yet been reformed, despite the fact that local public finance is on the verge of a crisis. The main reason for the deadlock in reform is considered to be the difficulty in obtaining a rationale for the empowerment of potential sectors.

The author of this paper proposed a rational approach to administrative evaluation in conjunction with a prospective way to the delegation of power from the public sector to other potential sectors (Sato, 2007). Specifically, rational matching process of projects of a local government with alternative sectors was

\footnotetext{
* Corresponding author
} 
developed by applying the Analytic Hierarchy Process (AHP) (Saaty, 1980). The process clarified both the property of each project of a local government and the characteristic of alternative sectors including the public sector. Based on the results of the study, principal component analys is concerning properties featuring projects of a local government is carried out in this paper. New concepts representing the aspect of the projects are extracted, which illustrate the structure of publicness and show the scheme of public sector reform.

Section 2 summarizes the matching process with projects of a local government with alternative sectors proposed by Sato (2007) in conjunction with the outputs of the study. Section 3 shows the results of principal component analys is and Section 4 concludes this paper.

\section{Summary of the previous study}

This section summarizes the outline of the study (Sato, 2007); the matching process and the subsequent results are shown. Those will be the basis of principal component analys is in Sect ion 3, which clarifies the scheme of public sector reform.

\subsection{Matching process of projects with sectors}

A system of public administration of a local government in Japan can be stratified as a hierarchical structure, consisting of philosophies, policies, measures, projects, and operations from the top to the bottom; all these activities are administered by the public sector so far. Among these activities, projects were focused on as objects of evaluation in the study. Inasmuch as empowering potential sectors would be crucial for successful reform, some sectors including public sector were focused on as alternatives to be delegated the authorities of public sector in the study.

The matching process was organized by three steps: in step 1, all projects of a local government were evaluated based on seven properties which define publicness listed below; in step 2, alternative sectors were characterized from the viewpoint of the seven properties; in step 3, overall judgments concerning the degree of conformance were derived.

\section{Seven properties}

Authority: the power or right to give orders or make decisions

Efficiency: skill in avoiding wasted time and effort

Coproductivity: done with or working with others for a common purpose or benefit

Publicity: affecting the people or community as a whole

Fairness: ability to make judgments free from discrimination or dishonesty

Profitability: the quality of affording ga in or benefit or profit

Disciplinary: having quality re lating to a specific field

These properties were derived by interviewing the executive personnel of a local government in ligh of appropriateness for the aforementioned evaluations and characterizations.

Step 1-Evaluation of projects

First, the all (266) projects were evaluated based on the seven properties, each of which is appropriate for featuring projects of a local government. In this step, the executive personnel of a local government were asked to evaluate projects they were in charge of. In a practical sense, they conducted pairwise comparisons from the viewpoint of the seven properties by the AHP for each project. Then the evaluation of each project was derived as a weight vector called $e$-vector which was normalized by $l_{1}$-norm and denoted $\boldsymbol{e}_{i}=\{$ weight of property $j\},(i=1, \ldots, 266 ; j=$ Authority, Efficiency, Coproductivity, Publicity, Fairness, Profitability, Disciplinary). In case that project $i$ was evaluated as $\boldsymbol{e}_{i}=(0.0324,0.0951,0.0951$, 
$0.4160,0.0444,0.0951,0.2218)$, the e-vector means that the project should be carried out with Publicity (4th-element), while Authority (1st-element) needed not to be highly weighted.

Step 2 - Characterization of alternative sectors

Next, the four alternative sectors were characterized from the viewpoint of the seven properties, which were the same as those employed in step 1. In this step, the executive personnel of a local government were asked to characterize alternative sectors; they individually conducted pairwise comparisons of the seven properties for each sector. Based on the pairwise-comparison matrices, the geometric mean of each element of the matrices was calculated and one pairwise comparison matrix was generated as a consensus-based matrix. Then the characteristic of each sector was elicited as a weight vector called $c$ vector which was normalized by $l_{1}$-norm and denoted $c_{j}=\{$ weight of sector $k\},(j=$ Authority, Efficiency, Coproductivity, Publicity, Fairness, Profitability, Disciplinary; $k=$ public sector, semi-public sector, agency, private sector). If property $j$ was evaluated as $\boldsymbol{c}_{j}=(0.6628,0.0847,0.1958,0.0540)$, the $c$-vector means that public sector (1st-element) partook the property most, while private sector (4th-element) did not. Furthermore, the matrix $C=\left(\boldsymbol{c}_{j}^{\mathrm{T}}\right)$ was defined as $C$-matrix and denoted $C$, which represents the characteristic of each sector. Actual $C$ obtained from the study is shown in Section 2.2.

Step 3-Overall judgment

Lastly, an overall judgment concerning the matching of projects with alternative sectors was derived by taking the weighted average of the evaluations of each project and the characteristics of sectors. In a practical sense, $C \cdot \boldsymbol{e}_{i}{ }^{\mathrm{T}}$ was defined as the degree of conformance for project $i(i=1, \ldots, 266)$. In case, the overall judgment for project $i$ was calculated as $C \cdot \boldsymbol{e}_{i}{ }^{\mathrm{T}}=(0.3780,0.1544,0.2126,0.2549)$, the weight of public sector (1st-element) was the highest and that of the semi-public sector (4th-element) was the lowest, which implies that the best-match sector with project $i$ was the public sector and the worst was the semi-public sector.

\subsection{Results}

Step 1 reads out the evaluations of the 266 projects of a local government. Table 1 shows part of the summary of this step. The largest elements are boldfaced; the smallest elements are shown in italics. In the aggregate, as shown in the last row of the table, Publicity and Coproductivity were highly weighted, while Profitability and Authority were not.

Table 1. Evaluation of projects (abstract).

\begin{tabular}{cccccccc}
\hline project & Authority & Efficiency & Coproductivity & Publicity & Fairness & Profitability & Disciplinary \\
\hline 1 & 0.0471 & 0.0348 & 0.2539 & 0.1464 & 0.4563 & 0.0349 & 0.0266 \\
2 & 0.0332 & 0.1794 & 0.4364 & 0.0833 & 0.1359 & 0.0561 & 0.0756 \\
3 & 0.1061 & 0.0407 & 0.0916 & 0.2064 & 0.2792 & 0.0317 & 0.2442 \\
& & & & & & & \\
266 & 0.4044 & 0.2453 & 0.0334 & 0.1051 & 0.0415 & 0.1296 & 0.0407 \\
\hline average & 0.0818 & 0.1167 & 0.1880 & 0.2318 & 0.1371 & 0.0652 & 0.1794 \\
\hline
\end{tabular}

Step 2 characterizes four alternative sectors including public sector. Table 2 presents the summary of Step 2. Each column is normalized by $l_{1}$-norm and the largest elements in each property (column) are boldfaced; the smallest elements are shown in italics. As shown in the table, each sector has its favored characteristics; the public sector excels at Authority, Publicity and Fairness; the semi-public sector excels at Coproductivity, and so on.

As the final output of the matching process proposed in the study, Table 3 summarizes the number of projects whose degree of conformance to each alternative sector was the highest, which is classified by the alternative sectors. At present, all 266 projects of the local government are administered by the public sector; the study, however, showed that 93 out of 266 projects $(35.0 \%)$ should be outsourced from the public sector to other sectors. As shown in the table, 38 projects (14.3\%) should devolve to a semi-public 
sector, $11(4.1 \%)$ to an agency and $44(16.5 \%)$ to a private sector. These results give quantitative outputs to administrative evaluation and rational bases for public sector reform.

Table 2. Character of alternative sectors (C-matrix).

\begin{tabular}{cccccccc}
\hline Sector & Authority & Efficiency & Coproductivity & Publicity & Fairness & Profitability & Disciplinary \\
\hline public & 0.6628 & 0.0623 & 0.0724 & 0.6678 & 0.6439 & 0.0361 & 0.1521 \\
semi-public & 0.0874 & 0.0982 & 0.6022 & 0.1254 & 0.1012 & 0.1923 & 0.0455 \\
agency & 0.1958 & 0.2012 & 0.2460 & 0.1522 & 0.1966 & 0.0721 & 0.3825 \\
private & 0.0540 & 0.6383 & 0.0794 & 0.0546 & 0.0583 & 0.6995 & 0.4199 \\
\hline
\end{tabular}

Table 3. Overall judgments.

\begin{tabular}{c}
\hline public \\
\hline 266 \\
$100.0 \%$ \\
\hline
\end{tabular}

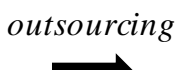

\begin{tabular}{cccc}
\hline public & semi-public & agency & private \\
\hline 173 & 38 & 11 & 44 \\
$65.0 \%$ & $14.3 \%$ & $4.1 \%$ & $16.5 \%$ \\
\hline
\end{tabular}

\section{Principal component analysis on publicness}

In this section, principal component analysis concerning the feature of publicness is carried out based on the results the study (Sato, 2007), and the goal of the social structure is considered in conjunction with public sector reform based on extracted new concepts representing the aspect of the projects of a local government.

In this analysis, the outputs of the step 1, i.e., 266 eigenvectors $\boldsymbol{e}_{i}(i=1, \ldots, 266)$ not-normalized by $l_{1}$ norm are employed. Table 4 summarizes the results of principal component analysis. As can be seen in the table, cumulative proportion of the top four components reaches $77.6 \%$; therefore, those four components, $\mathrm{C}_{m}(m=1, \ldots, 4)$ are employed to illustrate the aspect of projects of a local government. Table 5 shows the component score of each property; the maximum of absolute value of each column are boldfaced. As shown in Table 5, each component has the following features.

$$
\begin{aligned}
& \mathrm{C}_{1}: \text { Efficiency, Profitability: }+ \text {; Authority, Fairness: } \mp 0 \\
& \mathrm{C}_{2} \text { : Authority: ++; Coproductivity: -- } \\
& \mathrm{C}_{3}: \text { Publicity: - } \\
& \mathrm{C}_{4}: \text { Fairness: }++ \text {; Authority, Efficiency, Publicity: } \mp 0 ; \text { Disciplinary: - }
\end{aligned}
$$

Thus, in this paper, each extracted component can be defined as follows; $\mathrm{C}_{1}$ : degree of involvement of markets; $\mathrm{C}_{2}$ : degree of controllability of markets; $\mathrm{C}_{3}$ : degree of freedom of new entries; $\mathrm{C}_{4}$ : degree of openness of markets.

Table 4. Results of principal component analys is.

\begin{tabular}{ccccccc}
\hline \multirow{2}{*}{ component } & \multicolumn{2}{c}{ initial eigenvalue } & \multicolumn{2}{c}{ extracted sum of squares of loadings } \\
& sum & proportion & cumulative proportion & sum & proportion & cumulative proportion \\
\hline 1 & 1.7466 & 24.9511 & 24.9511 & 1.7466 & 24.9511 & 24.9511 \\
2 & 1.4867 & 21.2390 & 46.1901 & 1.4867 & 21.2390 & 46.1901 \\
3 & 1.1178 & 15.9684 & 62.1584 & 1.1178 & 15.9684 & 62.1584 \\
4 & 1.0780 & 15.3997 & 77.5582 & 1.0780 & 15.3997 & 77.5582 \\
5 & 0.7611 & 10.8733 & 88.4315 & & & \\
6 & 0.6806 & 9.7222 & 98.1537 & & & \\
7 & 0.1292 & 1.8463 & 100.0000 & & & \\
\hline
\end{tabular}

Table 5. Component score of each property.

\begin{tabular}{cccccccc}
\hline component & Authority & Efficiency & Coproductivity & Publicity & Fairness & Profitability & Disciplinary \\
\hline 1 & 0.0082 & 0.6570 & -0.5268 & -0.5339 & 0.0817 & 0.6430 & 0.5764 \\
\hline
\end{tabular}




\begin{tabular}{lccccccc}
\hline 2 & 0.7158 & -0.1798 & -0.7394 & 0.4376 & 0.3336 & -0.2566 & 0.1633 \\
3 & 0.2286 & -0.3573 & 0.2958 & -0.6674 & 0.4955 & -0.2733 & 0.2909 \\
4 & -0.0594 & 0.2415 & -0.0215 & -0.0070 & 0.7225 & 0.2329 & -0.6628 \\
\hline
\end{tabular}

Figure 1 is the distribution map of all projects with reference to $C_{1}$ and $C_{2}$-axises. In the figure, projects classified into "public" in Table 3 are shown as ' $x$,' and the remaining projects are shown as follows: "semi-public" as '○;' "agency" as ' $\diamond$;' and "private" as ' $\square$.' Furthermore, seven properties, such as Authority, are also plotted on the diagram. Since the distributions of projects and properties featuring publicness are extracted based on the administrative evaluation of projects of a local government, the figure could be interpreted as the goal of social structure.

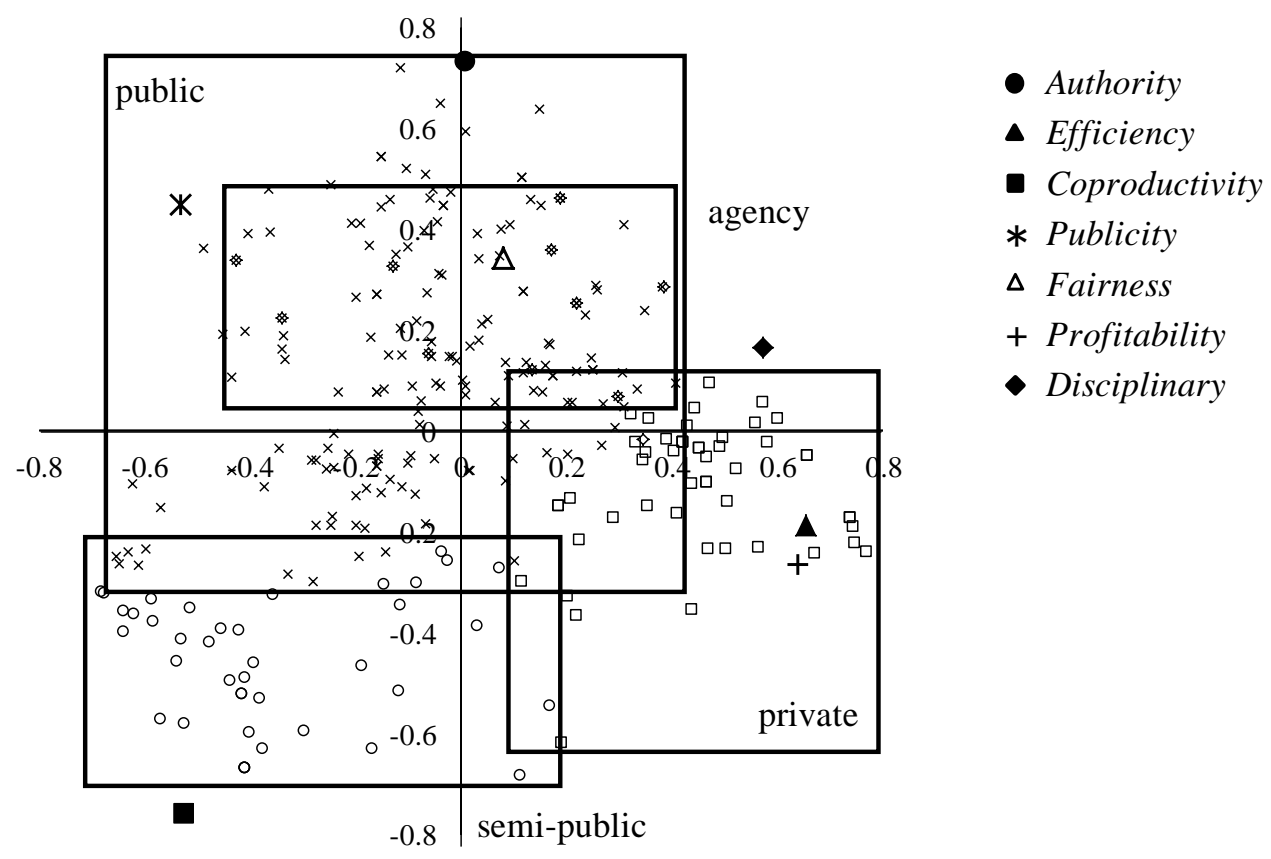

Figure 1. Distribution of the seven properties on $\mathrm{C}_{1} \mathrm{C}_{2}$-plane.

As shown in Figure 1, the $\mathrm{C}_{1} \mathrm{C}_{2}$-plane is roughly covered by the following four regions, which could be named as regions of the public sector, semi-public sector, agency and private sector with the following reasons. The region mainly spreading over the second quadrant includes such projects as to be shown as ' $\mathrm{x}$ ' that should be administrated by public sectors. The region is characterized by the properties of Authority, Publicity and Fairness, and its degree of $\mathrm{C}_{1}$ is low and that of $\mathrm{C}_{2}$ is high. Thus the area could be interpreted as the public sector region. In the same way, each region can be interpreted as follows.

The region in the third quadrant includes such projects as to be shown as ' $O$ ' that should be administrated by semi-public sectors. The region is featured by the property of Coproductivity, and its degree of $\mathrm{C}_{1}$ nor that of $\mathrm{C}_{2}$ is neither low, which could be considered as the semi-pubic sector region. The region ranging over the first and the second quadrant includes such projects as to be shown as ' $\nabla$ ' that should be administrated by agencies. The region is characterized by the properties of Disciplinary, Fairness and Publicity, and its degree of $\mathrm{C}_{2}$ is medium. Thus the area could be interpreted as the agency region. The region in the fourth quadrant includes such projects as to be shown as ' $\square$ ' that should be administrated by private sectors. The region is featured by the properties of Disciplinary, Efficiency and Profitability, and its degree of $\mathrm{C}_{1}$ is high and that of $\mathrm{C}_{2}$ is low, which could be considered as the private sector region.

This paper carries out principal component analysis concerning the properties featuring the projects of a local government based on the results of the previous study (Sato, 2007). In the context of public sector 
reform, assuming that the public sector would specialize in decision-making and ruling, the size and authority of administrative organizations should be reduced and that agency or other potential sector would take on an important role, particularly in executing projects. The results shown in Fig. 1 concludes that present public-private binary social structure should change and improve from public-private binary structure to ternary structure consisting of refined public sector, intermediate sector and private sector. Therefore, the results of this paper imply a new paradigm of publicness and illustrate the scheme of public sector reform. Leaving out the details, the results obtained from the analyses on the $\mathrm{C}_{1} \mathrm{C}_{3}$-plane and other planes support the implication of this analysis.

\section{Concluding remarks}

One of the main purposes of administrative evaluation is to provide a rational basis for public sector reform and to fulfill administrative accountability. Taking the tight fiscal conditions of local governments and citizens' claims for clarifying administrative responsibility into account, both rational administrative evaluation and subsequent public sector reform have been one of the most pressing issues for governors and personnel of local governments. In Japan, more than two-thirds of local authorities have introduced such evaluation systems, with some state industries having been privatize d to date. Nevertheless, several local governments in Japan are still immersed in financial crises. One of the reasons for the gap between introducing evaluation systems and the deadlock in reform is considered to stem from the style of evaluation reports, which adversely affects their quality. To be more precise, most reports of administrative evaluations are described qualitatively due to the lack of objective criteria. As a result, such evaluation systems are often criticized as "subjective." Even worse, the evaluations are carried out as self-appraisals, resulting in further criticism about their being lenient on themselves. Therefore, the employment of objective criteria and the introduction of external or third-party evaluations are necessary steps for enhancing evaluation systems' reliability. The author of this paper focused on the quantification of criteria that lead to a rational approach for administrative evaluation, including one prospective way to empower potential sectors in the process of public sector reform in the previous study (Sato, 2007). Specifically, how to match projects of a local government with alternative sectors rationally was introduced by using the AHP. The evaluations of projects and characteristics of sectors were thus quantitatively clarified, providing an objective basis for public sector reform. Based on the results the study, this paper extracts the new concepts representing the aspect of projects of a local government by using principal component analysis, which illustrates a new paradigm of publicness and shows the scheme of how to reform public sectors. Leaving out the details, these results were persuasive for administrative officials according to interviews following the survey. One executive personnel said, "Evaluating administrative activities is one thing; implementing reformations is another." Indeed, almost all local governments evaluate their administrative activities to a greater or lesser degree; a great many projects of the local government have not yet been reformed. Here we have open-ended questions: (1) how to deal with the nature of organization and its personnel, clinging to vested interests that prevent reformation within local government and (2) how to deal with so-called political maneuvers, which sometimes leave conventional projects unchanged. Further analyses based on case studies are necessary.

\section{REFERENCES}

Ministry of Internal Affairs and Communications. Report on the Activities of Administrative Evaluation in Local Public Authorities (in Japanese). Retrieved on March 1, 2011 from http//www.soumu.go.jp/

Saaty, T.L. (1980). The Analytic Hierarchy Process. McGraw-Hill, New York.

Sato, Y. (2007). Administrative Evaluation and Public Sector Reform: An Analytic Hierarchy Process Approach. International Transactions in Operational Research 14(5), 445-453. 
Yamamoto, K. (2008). Has Agencification Succeeded in Public Sector Reform? Realities and Rhetoric in the Case of Japan (in Japanese). Asia Journal of Political Science, 16(1), 24-40. 